\title{
Androgenic alopecia and dutasteride in hair mesotherapy: A short review
}

\section{Estela B Busanello, Elias Turcatel}

\author{
Research Institute Ana Carolina Puga, NEPUGA, Ribeirão Preto, SP, Brasil
}

Corresponding author: Dr. Estela B Busanello, E-mail: busanello.estela@gmail.com

\begin{abstract}
Androgenic alopecia (AGA) is the most common cause of patterned hair loss in predisposed men and women. AGA is a multifactorial and polygenetic condition, affecting up to $80 \%$ of men and $40-50 \%$ of women during life. AGA is characterized by a gradual reduction of the anagen and increase in telagen phase, leading to a progressive follicle miniaturization. As a consequence, terminal hairs are converted into vellus hairs decreasing hair density. The pathophysiology of AGA is heterogeneous and highly complex. A diverse combination of genetical factors, endocrine abnormalities, circulating androgens, drugs, diet and microinflammation in hair follicles of each individual are related to this condition. However, it is well known that androgens are the major modulators of male AGA but their specific action on female AGA is still under debate. Circulating testosterone is converted by $5 \alpha$-reductase in $5 \alpha$-dihydrotestosterone (DHT) in the periphery, a decrease of anagen phase occur, anticipating catagen phase in a complex process involving apoptosis as probably microinflammation. In AGA treatment, mesotherapy is being used with $5 \alpha$-reductase inhibitors, especially dutasteride, injected directly on scalp. Thus, this updated review summarized the injectable use of dutasteride based on data available on PubMed until March 2017. Dutasteride, a second-generation inhibitor of $5 \alpha$-reductase is more potent than finasteride due to the capability of inhibit types 1 and 2 of the enzyme. The efficacy and safety of hair mesotherapy with dutasteride were reported by distinct groups and the best results were achieved when this compound was used in combination with other substances, increasing hair growth. This result could be explained by the multifactorial pathophysiology of AGA, involving hair follicle sensitivity to DHT and microinflammation. Therefore, a multi-therapeutic approach seems to be more effective in AGA management. In conclusion, more studies are needed to establish protocols and to evaluate long- term dutasteride injections.
\end{abstract}

Key words: Androgenic alopecia; Dutasteride; Mesotherapy.

\section{INTRODUCTION}

Androgenic alopecia (AGA) is the most common cause of patterned hair loss in predisposed men and women. AGA is a multifactorial and polygenetic condition, affecting $80 \%$ of Caucasian men and $40-50 \%$ of Caucasian women during life [1-3]. In Asian and African populations, the prevalence descrease to about $14 \%$ in men $[4,5]$.

AGA is characterized by a gradual reduction of the anagen and increase in telagen phase, leading to a progressive follicle miniaturization. As a consequence, terminal hairs are converted into vellus hairs decreasing hair density. The patterned male hair loss is classified in seven degrees according to the stage, firstly described by Hamilton in the 1950s [1] and improved later by Norwood [6]. Two years later, Ludwig described the female hair loss scale [7].

Mesotherapy, that employs multiple microinjections of a mixture of compounds into the mesoderm, is a cosmetic tool used worldwide. In AGA treatment, mesotherapy is being used with $5 \alpha$-reductase inhibitors, especially dutasteride, injected directly on scalp. Thus, this updated review summarized the injectable use of dutasteride based on data available on PubMed until March 2017. 


\section{Pathophysiology of AG}

The pathophysiology of AGA is heterogeneous and highly complex. A diverse combination of genetical factors, endocrine abnormalities, circulating androgens, drugs, diet and microinflammation in hair follicles of each individual are related to this condition [8-10].

Despite that the inheritance mode is unknown, several gene polymorphisms were found in AGA. Mutations in $5 \alpha$ - reductase, aromatase, estrogen receptor $\alpha$ and others have been related on literature [9,11-14]. However, the strongest association with AGA development is made when genetic alterations occur in androgenic receptors. These alterations increase androgenic receptors expression especially in frontal and vertex regions [15], explaining the patterned hair loss [16].

It is well known that androgens are the major modulators of male AGA but their specific action on female AGA is still under debate [17-19]. Circulating testosterone is converted by $5 \alpha$-reductase in $5 \alpha$-dihydrotestosterone (DHT) in the periphery. This reductase present 3 isoforms: types 1,2 and 3 [20,21]. Type 1 is mainly found in the skin, especially hair follicles, sweat and sebaceous glands $[22,23]$ whereas type 2 is predominantly located in male genitalia and prostate but is also found in the inner root sheath of hair follicles [24]. DHT, which present 10 times more affinity to androgen receptors compared to testosterone, binds to these receptors in genetically predisposed hair follicles, impairing hair cycle. The landmark decrease of anagen phase occur, anticipating catagen phase in a complex process involving apoptosis as probably microinflammation $[10,25]$. The involvement of hair follicle microinflammation in AGA is being reported since the 1970s. This process that occurs at least in one-third of AGA cases [10,26-29] initiates at infundibulum mediated by bacteria, UV irradiation, chemical and/or mechanical stress. Keratinocytes rapidly respond to stressors releasing interleukin-l $\alpha$ $(\mathrm{IL}-1 \alpha)[30,31]$ that was shown to inhibit hair growth in vitro [32-34]. A transcriptional cascade is activated, increasing pro-inflammatory cytokines (IL- $1 \alpha$, IL-1 $\beta$, $\mathrm{TNF} \alpha$ ), chemokines (IL-8, MCPs), collagenases and others. Fibroblasts also respond to pro-inflammatory factors [35] and cellular defenses (neutrophils, $\mathrm{T}$ cells, Langerhans cells) are mobilized $[36,37]$. The inflammation usually persists and may lead to tissue remodeling via collagenases, generating a perifollicular fibrosis [10] and also to apoptosis that has been recently related to follicle miniaturization [25].

\section{Diagnosis of AGA}

The classic male pattern hair loss can be identified based on the Norwood scale however, a differential diagnosis is crucial to better evaluate this condition. Family history of baldness and the observation of a transition from large, thick, pigmented to thinner, shorter and nonpigmented vellus hairs are strong indicatives of this condition [38]. Thrichoscopy can be useful to evaluate the alteration in hair diameter [39] and the presence of inflammation and erythema on scalp should also be considered [38]. In women, polycystic ovary syndrome, congenital adrenal hyperplasia and other disorders related to hormonal metabolism are often related do AGA [40].

The physical examination is the landmark to diagnose AGA but some laboratory exams may help in patient assessment. The analysis of testosterone metabolism and thyrotropin levels can be useful to correlate AGA with hormones disorders when suspected [38,41]. Alteration in iron metabolism and nutricional deficiencies may also be involved in AGA [38].

\section{Dutasteride and the management of AGA}

The complex pathophysiology is a challenge in AGA treatment and, for this reason, the stop of progression and further thinning are the main goal. In addition, there is only two FDA-approved therapies: finasteride, a type II $5 \alpha$-reductase inhibitor that present well documented sexual adverse effects and minoxidil, a vasodilator that may present unwanted hair grow [42].

Dutasteride, a second-generation inhibitor of $5 \alpha$-reductase is more potent than finasteride due to the capability of inhibit types 1 and 2 of the enzyme. This leads to a $90 \%$ reduction of DHT serum levels whereas finasteride reduces only $70 \%$ [43]. The firsts short-term studies comparing dutasteride to finasteride emerged at the 2000s [44-46]. Olsen et al showed that 24 weeks dutasteride $2.5 \mathrm{mg}$ is more efficient than finasteride $5 \mathrm{mg}$ in men with AGA [44]. Similarly, dutasteride $0.5 \mathrm{mg}$ was also more potent than finasteride $1 \mathrm{mg}$ [46].

The safe and efficacy of dutasteride was also observed in long-term studies. A six-months phase III study showed tolerability and improvement of hair growth in AGA patients receiving $0.5 \mathrm{mg}$ /day dutasteride [45]. Recently, Chung and coworkers showed that dutasteride for more than 6 years was safe and increased terminal, vellus and total hair count in male AGA patients [47]. On 
the other hand, adverse effects to those presented by finasteride (alterations on erectile, ejaculatory functions and fertility) and its long half life (4 weeks) [42] are the main factors that contribute to the reluctance on the use of dutasteride in AGA. Thus, the local administration of dutasteride by mesotherapy and a consequent reduction of systemic side effects is a relevant tool on AGA treatment [48].

\section{Hair mesotherapy}

Mesotherapy consists in intradermal injections of pharmacological substances in a specific body region with minimal or no systemic effects [49]. This minimally invasive technique was introduced by Michael Pistor in 1958 to treat asthma but the patient's hear loss was also resolved. More than 50 years later, mesotherapy has been used in the treatement of hair loss, cellulite, wrinkles, scar reduction, melasma, and fat deposits. The combination of pharmaceuticals, vitamins, enzymes and other bioactive substances vary according to the indication since there is no standardized formulation $[49,50]$.

Hair mesotherapy, also called mesohair, is used to treat alopecia with injections directly on affected areas of scalp of patients with AGA up to type IV on NorwoodHamilton classification [51]. The objective is to improve local circulation and stimulate hair follicle environment by providing nutrients. There are few scientific studies showing an improvement of patterned hair loss and despite the lack of a standardized protocols, some chemicals are commonly used: finasteride, dutasteride, minoxidil, biotine, dexpanthenol and minerals.

The efficacy and safety of hair mesotherapy with dutasteride were reported by distinct groups [48,52,53]. In this regard, Abdallah and coworkers showed that a dutasteride-containing preparation (dutasteride $5 \mathrm{mg}$, D-panthenol $500 \mathrm{mg}$, biotin $20 \mathrm{mg}$ and pyridoxine $200 \mathrm{mg}$ in a final volume of $10 \mathrm{~mL}$ ) increased hair count in man with hair loss. A reverse correlation between hair loss duration and scored hair improvement was also observed in this study [48]. Increased hair diameter, thickness and other aspects were also found using mesotherapy in women with alopecia but using the same dutasteride-containing preparation [52]. The main question that arose from these early studies was regarding the specific role of dutasteride on these effects since the solutions also contained several vitamins. Thus, Sobhy and colleagues recently compared mesotherapy sessions with the same dutasteride-containing solution as previous works with pure dutasteride and saline in men. A trichogram analysis showed that the best result was achieved when dutasteride was used in combination with other substances, increasing hair growth [53]. This result could be explained by the multifactorial pathophysiology of AGA, involving hair follicle sensitivity to DHT and microinflammation. Therefore, a multi-therapeutic approach seems to be more effective in AGA management.

Besides being generally safe, hair mesotherapy may present undesirable effects. Some studies reported patchy hair loss [54] and cicatricial alopecia [55] after the injections. Multifocal scalp abscesses with fat necrosis was also reported [56]. These cases underlie the possible risks of hair mesotherapy, emphasizing the importance of the professional experience and the cocktail composition.

\section{CONCLUSION}

Hair mesotherapy is being increasingly used by dermatologists and hair specialists in several countries and is a good alternative to manage AGA. Better results are achieved when dutasteride-containing solutions are used and mesotherapy are early initiated. However, more studies are needed to establish protocols and to evaluate long- term dutasteride injections.

\section{REFERENCES}

1. Hamilton JB. Patterned loss of hair in man; types and incidence. Ann N Y Acad Sci. 1951;53:708-28.

2. Birch MP, Messenger AG. Genetic factors predispose to balding and non-balding in men. Eur J Dermatol. 2001;11:309-14.

3. Gan DC, Sinclair RD. Prevalence of male and female pattern hair loss in Maryborough. J Investig Dermatol Symp Proc. 2005;10:184-9.

4. Lee WS, Lee HJ. Characteristics of androgenetic alopecia in asian. Ann Dermatol. 2012;24(3):243-52.

5. Bas Y, Seckin HY, Kalkan G, Takci Z, Citil R, Önder Y, et al. Prevalence and types of androgenetic alopecia in north Anatolian population: A community-based study. J Pak Med Assoc. 2015;65:806-9.

6. Norwood OT. Male pattern baldness: classification and incidence. South Med J. 1975;68:1359-65.

7. Ludwig E. Classification of the types of androgenetic alopecia (common baldness) occurring in the female sex. Br J Dermatol. 1977;97:247-54.

8. Randall VA. Androgens and human hair growth. Clin Endocrinol (Oxf). 1994;40:439-57.

9. Ellis JA, Harrap SB. The genetics of androgenetic alopecia. Clin Dermatol. 2001;19:149-54.

10. Mahé YF, Michelet JF, Billoni N, Jarrousse F, Buan B, Commo S, et al. Androgenetic alopecia and microinflammation. Int J Dermatol. 2000;39:576-84. 
11. Ha SJ, Kim JS, Myung JW, Lee HJ, Kim JW. Analysis of genetic polymorphisms of steroid 5alpha-reductase type 1 and 2 genes in Korean men with androgenetic alopecia. J Dermatol Sci. 2003;31:135-41.

12. Hayes VM, Severi G, Padilla EJ, Morris HA, Tilley WD, Southey MC, et al. 5 alpha-Reductase type 2 gene variant associations with prostate cancer risk, circulating hormone levels and androgenetic alopecia. Int J Cancer. 2007;120:776-80.

13. Sawaya ME, Price VH. Different levels of 5alpha-reductase type I and II, aromatase, and androgen receptor in hair follicles of women and men with androgenetic alopecia. J Invest Dermatol. 1997;109:296-300.

14. Oh HS, Smart RC. An estrogen receptor pathway regulates the telogen-anagen hair follicle transition and influences epidermal cell proliferation. Proc Natl Acad Sci U S A. 1996;93:12525-30.

15. Banka N, Bunagan MJ, Shapiro J. Pattern hair loss in men: diagnosis and medical treatment. Dermatol Clin. 2013;31:129-40.

16. Ellis JA, Stebbing M, Harrap SB. Polymorphism of the androgen receptor gene is associated with male pattern baldness. J Invest Dermatol. 2001;116:452-5.

17. Olsen EA. Female pattern hair loss. J Am Acad Dermatol. 2001;45:S70-80.

18. Ioannides D, Lazaridou E. Female pattern hair loss. Curr Probl Dermatol. 2015;47:45-54.

19. Torres F, Tosti A. Female pattern alopecia and telogen effluvium: figuring out diffuse alopecia. Semin Cutan Med Surg. 2015;34:67-71.

20. Kaufman KD. Androgen metabolism as it affects hair growth in androgenetic alopecia. Dermatol Clin. 1996;14:697-711.

21. Godoy A, Kawinski E, Li Y, Oka D, Alexiev B, Azzouni F, et al. $5 \alpha$-reductase type 3 expression in human benign and malignant tissues: a comparative analysis during prostate cancer progression. Prostate. 2011;71:1033-46.

22. Sato T, Sonoda T, Itami S, Takayasu S. Predominance of type I 5 alpha-reductase in apocrine sweat glands of patients with excessive or abnormal odour derived from apocrine sweat (osmidrosis). $\mathrm{Br} \mathrm{J}$ Dermatol. 1998;139:806-10.

23. Thiboutot D, Harris G, Iles V, Cimis G, Gilliland K, Hagari S. Activity of the type 15 alpha-reductase exhibits regional differences in isolated sebaceous glands and whole skin. J Invest Dermatol. 1995;105:209-14.

24. Chen W, Zouboulis CC, Orfanos CE. The 5 alpha-reductase system and its inhibitors. Recent development and its perspective in treating androgen-dependent skin disorders. Dermatology. 1996;193:177-84.

25. Ramos PM, Brianezi G, Martins AC, da Silva MG, Marques ME, Miot HA. Apoptosis in follicles of individuals with female pattern hair loss is associated with perifollicular microinflammation. Int J Cosmet Sci. 2016;38:651-4.

26. Lattanand A, Johnson WC. Male pattern alopecia a histopathologic and histochemical study. J Cutan Pathol. 1975;2:58-70.

27. Jaworsky C, Kligman AM, Murphy GF. Characterization of inflammatory infiltrates in male pattern alopecia: implications for pathogenesis. Br J Dermatol. 1992;127:239-46.

28. Whiting DA. Diagnostic and predictive value of horizontal sections of scalp biopsy specimens in male pattern androgenetic alopecia. J Am Acad Dermatol. 1993;28:755-63.

29. Young JW, Conte ET, Leavitt ML, Nafz MA, Schroeter AL. Cutaneous immunopathology of androgenetic alopecia. J Am Osteopath Assoc. 1991;91:765-71.

30. Lee RT, Briggs WH, Cheng GC, Rossiter HB, Libby P, Kupper T. Mechanical deformation promotes secretion of IL-1 alpha and IL-1 receptor antagonist. J Immunol. 1997;159:5084-8.

31. Kupper TS, Groves RW. The interleukin-1 axis and cutaneous inflammation. J Invest Dermatol. 1995;105:62S-6S.

32. Harmon CS, Nevins TD. IL-1 alpha inhibits human hair follicle growth and hair fiber production in whole-organ cultures. Lymphokine Cytokine Res. 1993;12:197-203.

33. Philpott MP, Sanders D, Kealey T. Cultured human hair follicles and growth factors. J Invest Dermatol. 1995;104:44S-5S.

34. Mahé YF, Buan B, Billoni N, Loussouarn G, Michelet JF, Gautier B, et al. Pro-inflammatory cytokine cascade in human plucked hair. Skin Pharmacol. 1996;9:366-75.

35. Smith RS, Smith TJ, Blieden TM, Phipps RP. Fibroblasts as sentinel cells. Synthesis of chemokines and regulation of inflammation. Am J Pathol. 1997;151:317-22.

36. Huber AR, Kunkel SL, Todd RF, Weiss SJ. Regulation of transendothelial neutrophil migration by endogenous interleukin- 8 . Science. 1991;254:99-102.

37. Nakamura K, Williams IR, Kupper TS. Keratinocyte-derived monocyte chemoattractant protein 1 (MCP-1): analysis in a transgenic model demonstrates MCP-1 can recruit dendritic and Langerhans cells to skin. J Invest Dermatol. 1995;105:635-43.

38. Shapiro J, Wiseman M, Lui H. Practical management of hair loss. Can Fam Physician. 2000;46:1469-77.

39. Chiramel MJ, Sharma VK, Khandpur S, Sreenivas V. Relevance of trichoscopy in the differential diagnosis of alopecia: A crosssectional study from North India. Indian J Dermatol Venereol Leprol. 2016;82:651-8.

40. Ramos PM, Miot HA. Female Pattern Hair Loss: a clinical and pathophysiological review. An Bras Dermatol. 2015;90:529-43.

41. Vincent M, Yogiraj K. A Descriptive Study of Alopecia Patterns and their Relation to Thyroid Dysfunction. Int J Trichology. 2013;5:57-60.

42. Rogers NE, Avram MR. Medical treatments for male and female pattern hair loss. J Am Acad Dermatol. 2008;59:547-66; quiz 67-8.

43. Clark RV, Hermann DJ, Cunningham GR, Wilson TH, Morrill BB, Hobbs S. Marked suppression of dihydrotestosterone in men with benign prostatic hyperplasia by dutasteride, a dual 5alpha-reductase inhibitor. J Clin Endocrinol Metab. 2004;89:2179-84.

44. Olsen EA, Hordinsky M, Whiting D, Stough D, Hobbs S, Ellis ML, et al. The importance of dual 5alpha-reductase inhibition in the treatment of male pattern hair loss: results of a randomized placebo-controlled study of dutasteride versus finasteride. J Am Acad Dermatol. 2006;55:1014-23.

45. Eun HC, Kwon OS, Yeon JH, Shin HS, Kim BY, Ro BI, et al. Efficacy, safety, and tolerability of dutasteride $0.5 \mathrm{mg}$ once daily in male patients with male pattern hair loss: a randomized, doubleblind, placebo-controlled, phase III study. J Am Acad Dermatol. 2010;63:252-8.

46. Gubelin Harcha W, Barboza Martínez J, Tsai TF, Katsuoka K, Kawashima M, Tsuboi R, et al. A randomized, active- and placebocontrolled study of the efficacy and safety of different doses of dutasteride versus placebo and finasteride in the treatment of male subjects with androgenetic alopecia. J Am Acad Dermatol. 2014;70:489-98.e3.

47. Chung HC, Lee S, Lee WS. Long-term efficacy and safety of the dual 5-alpha reductase blocker dutasteride on male androgenetic alopecia patients. J Dermatol. 2016.

48. Abdallah M, El-Zawahry K, Besar H. Mesotherapy using dutasteride-containing solution in male pattern hair loss: a controlled pilot study. PALD. 2009; 20:137-45.

49. Sivagnanam G. Mesotherapy - The french connection. J Pharmacol Pharmacother. 2010;1:4-8.

50. Atiyeh BS, Ibrahim AE, Dibo SA. Cosmetic mesotherapy: between scientific evidence, science fiction, and lucrative business. Aesthetic Plast Surg. 2008;32:842-9.

51. Price VH, Menefee E, Sanchez M, Ruane P, Kaufman KD. Changes in hair weight and hair count in men with androgenetic alopecia after treatment with finasteride, $1 \mathrm{mg}$, daily. J Am Acad Dermatol. 2002;46:517-23.

52. Moftah N, Abd-Elaziz G, Ahmed N, Hamed Y, Ghannam B, Ibrahim M. Mesotherapy using dutasteride-containing preparation in treatment of female pattern hair loss: photographic, morphometric and ultrustructural evaluation. J Eur Acad Dermatol Venereol. 2013;27:686-93.

53. Sobhy N, Aly H, El Shafee A, El Deeb M. Evaluation of the 
www.odermatol.com

effect of injection of dutasteride as mesotherapeutic tool in treatment of androgenetic alopecia in males. Our Dermatol Online. 2013;4:40-5.

54. El-Komy M, Hassan A, Tawdy A, Solimon M, Hady MA. Hair loss at injection sites of mesotherapy for alopecia. J Cosmet Dermatol. 2017.

55. Duque-Estrada B, Vincenzi C, Misciali C, Tosti A. Alopecia secondary to mesotherapy. J Am Acad Dermatol. 2009;61:707-9.

56. Kadry R, Hamadah I, Al-Issa A, Field L, Alrabiah F. Multifocal scalp abscess with subcutaneous fat necrosis and scarring alopecia as a complication of scalp mesotherapy. J Drugs Dermatol. 2008; $7: 72-3$.

Copyright by Estela B Busanello and Elias Turcatel. This is an openaccess article distributed under the terms of the Creative Commons Attribution License, which permits unrestricted use, distribution, and reproduction in any medium, provided the original author and source are credited.

Source of Support: Nil, Conflict of Interest: None declared. 